\title{
Analisis Kepuasan Pengguna Website Pajak Online Kota Bandung Menggunakan Model Evaluasi Terintegrasi
}

\author{
Resti Kartika Dewi', Ricky Firmansyah ${ }^{2}$ \\ 1,2 Universitas Bina Sarana Informatika \\ email:witra.thyka@gmail.com, ricky.rym@bsi.ac.id
}

\begin{abstract}
Regional tax is a tax payer paid by a personal or institution to the region without a balanced direct benefit, that can be eforced under applicable laws and regulation. The tax is used to finance regional implementation and regional development. Bandung government city by the tax office has launced a service tax application on May 31 ${ }^{\text {st }}$, 2016. Website sipp.disyanjak.bandung.go.id is made to facilitate the tax payer in consultation and get informations are related to property tax service (PBB) by internet. This research uses an integration model that includes information success system model by Delone and Mclean, acceptance model of UTAUT, and conformity model of HOT Fit with modification. The data used are primary data that obtained by questionnaire surveyto employees of service tax office and Bandung society who has been using the website sipp.disyanjak.bandung.go.id as a media of information with the sample of 100 peoples. The data processed with SPSS software version 22. Result of this research indicated that user are satisfied with the quality of information, quality of service, quality of system from the website sipp.disyanjak.bandung.go.id information system. The user are intend and plan to continue to use the website sipp.disyanjak.bandung.go.id information system, because they can improves their performance, easy to learn and used, then supported by colleagues who are using and consider it important. Usability intention has significant effect on net benefits, it is enough perceived by user that information system of website sipp.disyanjak.bandung.go.id are help respondents to det information about the taxes.
\end{abstract}

\section{Key Word: Conformity model of HOT Fit, Delone and Mclean, Tax, UTAUT, Website}

\begin{abstract}
Abstrak
Pajak daerah merupakan iuran wajib pajak yang dilakukan oleh orang pribadi atau badan kepada daerah tanpa imbalan langsung yang seimbang, yang dapat dipaksakan berdasarkan peraturan perundang-undangan yang berlaku. Pajak tersebut digunakan untuk membiayai penyelenggaraan daerah dan pembangunan daerah. Pemerintah kota Bandung melalui Dinas Pelayanan Pajak (Disyanjak) meluncurkan aplikasi pelayanan pajak pada tanggal 31 Mei 2016. Website sipp.disyanjak.bandung.go.id dibuat untuk mempermudah wajib pajak dalam berkonsultasi dan memperoleh informasi terkait pelayanan pajak bumi dan bangunan (PBB) melalui intranet. Penelitian ini dilakukan dengan menggunakan model integrasi model kesuksesan sistem informasi DeLone dan McLean, model penerimaan UTAUT, dan model kesesuaian HOT Fit dengan modifikasi. Data yang digunakan adalah data primer yang diperoleh melalui survei kuesioner kepada pegawai Dinas Pelayanan Pajak dan masyarakat kota Bandung yang telah menggunakan Website sipp.disyanjak.bandung.go.id sebagai media informasi dengan sampel sebanyak 100 orang. Data diolah menggunakan software SPSS versi 22. Hasil penelitian ini menunjukkan bahwa pengguna merasa puas terhadap kualitas informasi, kualitas layanan, dan kualitas sistem dari sistem informasi website sipp.disyanjak.bandung.go.id. Pengguna berniat dan berencana untuk terus menggunakan sistem informasi website sipp.disyanjak.bandung.go.id karena merasa dapat meningkatkan kinerjanya, cukup mudah dipelajari dan digunakan, serta didukung oleh rekan kerja yang juga menggunakan dan menganggapnya penting. niat penggunaan berpengaruh signifikan terhadap manfaat bersih, hal ini cukup dirasakan pengguna bahwa sistem informasi website sipp.disyanjak.bandung.go.id membantu responden memperoleh informasi mengenai pajak.
\end{abstract}

Kata Kunci: Conformity model of HOT Fit, Delone and Mclean, Tax, UTAUT, Website

\section{Pendahuluan}

Diterima Februari 10, 2019; Revisi Maret 16 , 2019; Disetujui Maret 18, 2019 
Pendapatan Daerah adalah semua hak daerah yang diakui sebagai penambahan nilai kekayaan bersih dalam periode tahun anggaran yang bersangkutan (Yustisia, 2015). Pendapatan daerah dibagi menjadi beberapa bagian yaitu Pendapatan Asli Daerah (PAD), Pendapatan Transfer, Pendapatan Daerah yang Sah (Pasal 1 poin 35 UU No.23 Tahun 2014).

Dari semua komponen sumber pendapatan daerah diatas, penerimaan dari pajak daerah memberikan kontribusi yang paling besar terhadap Pendapatan Asli Daerah (PAD) (Soemitro, 2014). UU Nomor. 28 Tahun 2009 menjelaskan bahwa pajak daerah merupakan iuran wajib pajak yang dilakukan oleh orang pribadi atau badan kepada daerah tanpa imbalan langsung yang seimbang, yang dapat dipaksakan berdasarkan peraturan perundang-undangan yang berlaku.

Pemerintah Indonesia melakukan berbagai upaya untuk mengoptimalkan penerimaan pajaknya, salah satunya adalah dengan melakukan reformasi perpajakan yaitu mengubah sistem pemungutan pajak dari official assessment system menjadi self assessment system.

Menurut (Resmi, 2015) "Official assessment system adalah suatu sistem pemungutan pajak yang dalam menentukan jumlah pajak terutangnya di tentukan oleh pemerintah (fiskus). Sedangkan, self assessment system merupakan jenis sistem pemungutan dengan adanya peran aktif dari wajib pajak untuk menghitung, memperhitungkan, menyetor, dan melapor sendiri kewajiban perpajakannya".

Artinya penerimaan pajak menjadi sumber pendapatan yang semakin hari semakin penting karena digunakan sebagai pembiayaan dan pembangunan.

Maka pemerintah melalui Direktorat Jenderal Pajak (DJP) bekerja keras dan berpikir bagaimana cara memberikan pelayanan kepada masyarakat atau wajib pajak agar hasil yang diharapkan adalah baik dan memuaskan sesuai dengan standarisasi pelayanan perpajakan. Bila sebelumnya pengelolaan pajak dilakukan secara manual yang membutuhkan banyak waktu dan kertas, saat ini pengolahan pajak diubah dengan menggunakan sistem teknologi informasi dan komunikasi.

Pemerintah Kota Bandung melalui Dinas Pelayanan Pajak (Disyanjak) meluncurkan aplikasi pelayanan pajak pada tanggal 31 Mei 2016. Dengan adanya layanan aplikasi ini, masyarakat yang ingin berkonsultasi dan memperoleh informasi terkait pelayanan pajak bumi dan bangunan (PBB) cukup mengakses situs sipp.disyanjak.bandung.go.id. Dalam surat kabar merdeka.com - Bandung, Wali Kota Bandung Ridwan Kamil menuturkan dalam satu bulan, rata-rata 2300 orang yang datang ke kantor Disyanjak untuk menanyakan persoalan sederhana. Dengan adanya aplikasi ini masyarakat tidak perlu lagi mengantri berjam-jam hanya untuk mengkonsultasikan hal-hal yang dapat diakses sendiri.

Ada dua (2) permasalahan utama yang dihadapi oleh Disyanjak dalam pelayanan publik khususnya pelayanan publik Pajak Bumi dan Bangunan (PBB). Permasalahan tersebut adalah :

1. Kebutuhan masyarakat terhadap ketersediaan dan kemudahan akses informasi dengan data-data PBB yang cepat, tepat dan akurat khususnya yang menyangkut informasi PBB. Dengan kemudahan akses terhadap informasi-informasi PBB, dapat berkorelasi terhadap penerimaan di sektor PBB, karena WP dapat dengan mudah mengetahui data tagihan PBB sehingga mempercepat proses pembayarannya, tanpa harus menunggu SPPT terlebih dahulu.

2. Jumlah Wajib Pajak (WP) yang datang langsung ke tempat pelayanan PBB Disyanjak untuk mendapatkan pelayanan PBB berdasarkan data tahun 2013, 2014 dan tahun 2015 adalah sebanyak 80.484 WP. Pelayanan PBB online yang diperlukan terutama terkait dengan kegiatan pendaftaran permohonan PBB secara online dan monitoring terhadap proses pelayanan tersebut.

Mengingat pentingnya peranan pajak yaitu sebagai salah satu sumber penerimaan Negara dalam menopang pembiayaan pembangunan dan penggambaran kemandirian ekonomi, maka penulis tertarik untuk meneliti sebuah aplikasi pajak online berbasis website yang ada di Kota Bandung yaitu sipp.disyanjak.bandung.go.id. Penelitian ini mengusulkan model evaluasi integrasi dari model penerimaan UTAUT (Unified Theory Of Acceptance and Usage of Technology), 
model kesuksesan sistem informasi Delone dan McLean dan model kesesuaian manusia-organisasi-teknologi HOT Fit (Human-Organization-Technology Fit) yang nantinya dapat menggambarkan kepuasan pengguna dari website pajak online dari Kota Bandung tersebut.

Berdasarkan latar belakang permasalahan, dapat disimpulkan bahwa pajak adalah iuran yang dibayarkan secara paksa baik perseorangan maupun badan kepada Negara atau Daerah untuk membiayai belanja Negara / Daerah sesuai dengan kebijakan yang berlaku. Untuk mengukur tingkat kepuasan dari pengguna aplikasi pajak online di Kota Bandung ini peniliti menggunakan model evaluasi integrasi dari model penerimaan UTAUT (Human-Organization-Technology Fit), model kesuksesan sistem informasi Delone dan McLean dan model kesesuaian manusia-organisasi-teknologi HOT Fit (Human-Organization-Technology Fit), maka perumusan masalahnya yaitu :

1. Apakah faktor manusia (Human Factor), faktor organisasi (Factor Organization), dan faktor teknologi (Technology Factor) berpengaruh terhadap minat pengguna (Behavioural Intention / Intention to Use) website pajak online Bandung?

2. Apakah minat pengguna (Behavioural Intention / Intention to Use) website pajak online berpengaruh terhadap kepuasan pengguna (User Satisfication)?

3. Apakah kepuasan pengguna (User Satisfication) website pajak online berpengaruh terhadap manfaat bersih (Net Benefit) ?

4. Apakah terdapat hubungan kesesuaian antara faktor manusia (Human Factor) dan faktor organisasi (Organization Factor), antara faktor organisasi (Organization Factor) dan faktor teknologi (Technology Factor), serta antara factor manusia (Human Factor) dan faktor teknologi (Technology Factor)?

\section{Metode Penelitian}

Tahapan penelitian yang dilakukan oleh penulis yaitu sebagai berikut :

1. Mengidentifikasi dan Perumuskan Masalah

Penulis mengidentifikasi dan merumuskan masalah dengan bentuk pertanyaan yang dijawab pada maksud penelitian.

2. Merumuskan Hipotesis

Penulis membuat rumusan hipotesis yang merupakan pertanyaan atau anggapan yang sifatnya sementara tentang fenomena tertentu yang akan diselidiki. Hipotesis ini dibuat berdasarkan variabel dan indikator yang terdapat pada model Unified Theory of Acceptance and Usage of Technology (UTAUT), Delone dan Mclean, serta Model Human, Organization, Technologi Fit (HOT Fit).

3. Studi Kepustakaan

Penulis melakukan studi kepustakaan berdasarkan teori-teori yang sudah ada.

4. Menentukan Sampel Penelitian

Penulis menentukan sampel penelitian berdasarkan populasi. Sampel digunakan untuk mewakili dari keseluruhan populasi yang ada. Dimana penulis menggunakan Teknik Non-Probability Sampling yaitu dengan teknik Sampling Insiden dan Sampling purposive.

5. Mangumpulkan Data

Penulis mengumpulkan data, sebagai bahan baku informasi yang harus dicari. Dalam hal ini penulis melakukan pengumpulan data melalui metode survei, dan penulis memperoleh data primer dengan cara menyebarkan kuesioner yang berisiskan pertanyaanpertanyaan. Pengumpulan data yang dilakukan penulis dimulai dari menentukan instrument penelitian, menentukan variabel dan indikator, serta menyusun kuesioner.

6. Uji Validitas dan Reliabilitas

Uji validitas digunakan untuk mengukur sah atau valid tidaknya sebuah kuesioner, sedangkan uji reliabilitas digunakan untuk mengetahui apakah instrumen yang ada dalam sebuah penelitian itu dapat dipercaya.

7. Mengelola dan Menyajikan Data

Setelah data terkumpul, penulis mengelola dan menyajikan data sehingga informasi atau data yang tersaji lebih mudah diinterpretasikan dan analisis lebih lanjut.

8. Menganalisis Data

Hasil olahan dianalisis lebih lanjut dengan menggunakan alat-alat analisis yang sesuai dengan tujuan riset agar 
menghasilkan kajian yang cukup tajam, mendalam, dan luas. Analisis data yang dilakukan oleh penulis dibagi menjadi dua bagian yaitu analisis deskriptif dan analisis statistik, dimana analisis deskriptif yang dihasilkan berbentuk tabel frekuensi yang memberikan gambaran terhadap objek yang diteliti melalui data sampel (Sugiyono, 2013:29). Sedangkan analisis statistik digunakan untuk membuat generalisasi-generalisasi mengenai karakteristik-karakteristik populasi berdasarkan data dari sample yang diambil dari populasi (Neolaka, 2014:7). Pengujian statistik yang digunakan adalah dengan uji asumsi klasik. Uji asumsi klasik dalam penelitian ini terdiri dari uji normalitas, uji autokorelasi, uji multikolineritas dan

uji heteroskedastisitas.

9. Kesimpulan dan Saran

Setelah melakukan analisis, penulis membuat generalisasi penemuannya berdasarkan batasan-batasan penelitian yang ada, serta membuat kesimpulan yang sesuai dengan hipotesis yang diajukan.

\section{Analisis Faktor Kepuasan Pengguna}

A. Model Unified Theory of Acceptance and Usage of Technology (TAM)

Model Unified Theory of Acceptance

and Usage of Technology (UTAUT) menjelaskan bagaimana pengaruh perbedaan individu dalam menggunakan teknologi namun belum menghubungkan ke hasil-hasil pemakaian. Venkatesh et al dalam (Yuliasari, 2014) "mengkaji teori-teori tentang penerimaan teknologi oleh pemakai-pemakai sistem". Model UTAUT dikembangkan menjadi sebuah model baru terintegrasi yang merupakan teori gabungan dari delapan teori yang dikaji yaitu Theory of Reasoned Action / TRA, Technology Acceptance Model / TAM, Motivational Model / MM, Theory of Planned Behavior / TPB, TAM + TPB, Model of PC Utilization / MPCU, Innovation Diffusion Theory / IDT dan Social Cognitive Theory / SCT.

Setelah mengevaluasi atau mengkaji kedelapan model diatas (Venkatesh, 2003) menjelaskan "Terdapat empat konstruk I variable dalam model UTAUT yaitu harapan kinerja (performance expectancy), harapan usaha (effort expectancy), pengaruh sosial (social influence), dan kondisi-kondisi fasilitas (facilitating conditions)". Keempat konstruk ini mempengaruhi perilaku niat untuk menggunakan teknologi. Selain keempat variable tersebut, terdapat empat mediator lainnya yang berfungsi sebagai mediator yang memperkuat pengaruh keempat variable utama terhadap penerimaan maupun penggunaan teknologi. (Brown, 2005) menyatakan bahwa "Keempat mediator tersebut adalah jenis kelamin (Gender), umur (Age), pengalaman (Experience), dan kesukarelaan Voluntariness Of Use)". Kemudian (Venkatesh, 2003) menjelaskan dan mendeskripsikan empat konstruk utama dalam metode UTAUT (Unified Theory of Acceptance and Usage of Technology) yaitu :

1. Harapan kinerja (performance expectancy) didefinisikan sebagai seberapa tinggi seseorang percaya bahwa menggunakan suatu sistem akan membantu dia mendapatkan keuntungan kinerja pekerjaannya.

2. Harapan usaha (effort expectancy) didefinisikan sebagai tingkat kemudahan yang dihubungkan dengan penggunaan suatu sistem. Kalau sistem mudah digunakan maka usaha yang dilakukan tidak akan terlalu tinggi dan sebaliknya jika suatu sistem sulit digunakan maka diperlukan usaha yang tinggi,

3. Pengaruh sosial (social influence) didefinisikan sebagai sejauh mana seorang individual mempersepsikan kepentingan yang dipercaya oleh orang lain yang akan mempengaruhinya menggunakan sistem yang baru.

4. Kondisi-kondisi fasilitas (facilitating conditions) didefinisikan sebagai sejauh mana seseorang percaya bahwa infrastruktur organisasional dan teknikal tersedia untuk mendukung sistem.

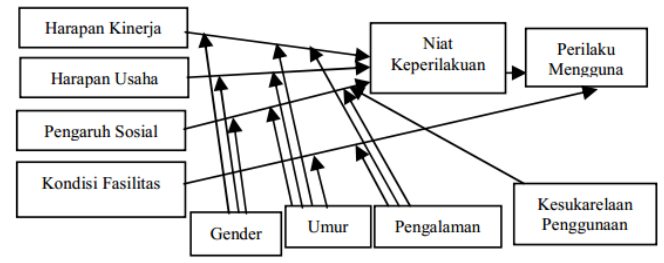

Gambar 1. Model UTAUT Sumber : (Venkatesh, 2003)

B. Model Kesuksesan Delone dan
Mclean 
Penerapan sistem teknologi informasi diharapkan akan berhasil dan sukses berjalan sesuai dengan keinginan organisasi. Aplikasi dapat dikatakan sukses jika faktor kualitas sistem dan kualitas informasi yang dihasilkan aplikasi tersebut mampu memberikan rasa puas terhadap pengguna sehingga pengguna bersedia untuk menggunakannya lagi dan akhirnya dapat meningkatkan kinerja pengguna (Elvandari, 2011). Menurut (Jogiyanto, 2007) "Model yang baik adalah model yang lengkap tetapi sederhana atau disebut model parsimoni". Berdasarkan teori yang telah dikaji (McLean, 1992) mengembangkan suatu model parsimoni dengan nama model kesuksesan sistem informasi Delone dan McLean atau yang di kenal dengan model original Delone dan McLean.

Menurut (F. Kursehi, 2013) menjelaskan bahwa "Faktor atau komponen pengukuran kesuksesan SI dari model ini adalah kualitas sistem (system quality), kualitas informasi (information quality), penggunaan (use), kepuasan pengguna (user satisfaction), dampak individual (individual impact), dan dampak organisasi (organization impact)".

Berdasarkan kritik yang diterima dan perkembangan Sistem Informasi (SI) serta lingkungan penggunaannya, (McLean., 2003) memperbarui modelnya yaitu dengan memasukkan variabel kualitas pelayanan (service quality), merubah variabel-variabel dampak individual dan organisasi menjadi manfaat-manfaat bersih (net benefit), serta perbaikan dan peningkatan pengukuranpengukuran. Komponen-komponen tersebut disusun dengan urutan pengukuran sebagai berikut:

1. Sistem informasi dibuat dan diukur kualitasnya dengan tiga dimensi kualitas, yaitu kualitas informasi, kualitas sistem, dan kualitas layanan.

2. Sistem informasi dipakai dan pengalaman pemakainya ini diukur dengan dua dimensi yaitu, dimensi penggunaan dan dimensi kepuasan pengguna.

3. Dampak dari pemakaian yang diukur dengan dua dimensi yaitu, individual impact dan organizational impact (net benefit).

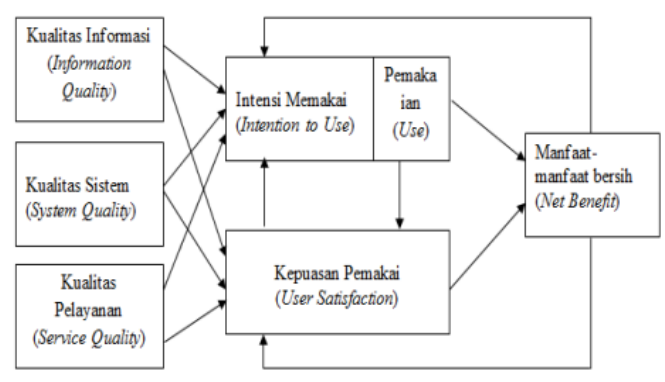

Gambar 2. Model Kesuksesan Delone dan McLean

Sumber : (Jogiyanto, 2007)

\section{Model Human, Organization, Technologi Fit (HOT Fit)}

Model yang dikembangkan oleh (Yusof, 2006) ini menempatkan komponen penting dalam sistem informasi yakni manusia (human), organisasi (organization), dan teknologi (technology) serta kesesuaian hubungan diantaranya. Kerangka model HOT Fit merupakan pengembangan model kesuksesan SI DeLone dan McLean yaitu menambahkan faktor organisasi dan dimensinya, struktur dan lingkungan, fit antara factor teknologi, manusia dan organisasi, dua cara hubungan antara dimensi kualitas informasi dan penggunaan sistem, kualitas informasi dan kepuasan penggunaan, struktur dan lingkungan, struktur dan net benefit, dan lingkungan dan net benefit. (Yusof, 2008) menjelaskan tentang komponen yang ada dalam Hot Fit yaitu :

1. Manusia (Human) menilai sistem informasi dari sisi penggunaan sistem (system use) pada frekuensi dan luasnya fungsi dan penyelidikan sistem informasi. System use juga berhubungan dengan siapa yang menggunakan (who use it), tingkat penggunanya (level of user), pelatihan, pengetahuan, harapan, dan sikap menerima (acceptance) atau menolak (resistance) sistem. Komponen ini juga menilai sistem dari aspek kepuasan pengguna (user satisfaction).

2. Organisasi (Organization) menilai sistem dari aspek struktur organisasi dan lingkungan organisasi. Struktur organisasi terdiri dari tipe, kultur, politik, hierarki, perencanaan dan pengendalian sistem, strategi, manajemen, dan komunikasi. Kepemimpinan, dukungan dari top manajemen atau manajemen puncak 
JURNAL SWABUMI, Vol. 7 No.1 Maret 2019, pp. 1 13

ISSN: 2355-990X

E-ISSN:2549-5178

6

dan dukungan staf merupakan bagian yang penting dalam mengukur keberhasilan sistem. Sedangkan lingkungan organisasi terdiri dari sumber pembiayaan, pemerintahan, politik, kompetisi, hubungan interorganisasional, dan komunikasi.

3. Teknologi (Technology) terdiri dari kualitas sistem (system quality), kualitas informasi (information quality), dan kualitas layanan (service quality). Kualitas sistem menyangkut keterkaitan fitur dalam sistem termasuk performa sistem dan user interface. Kemudahan penggunaan (ease of use), kemudahan untuk dipelajari (ease of learning), response time, usefulness, ketersediaan, fleksibilitas, dan sekuritas merupakan variabel atau faktor yang dapat dinilai dari kualitas sistem. Kualitas informasi berfokus pada informasi yang dihasilkan oleh sistem informasi. Kriteria yang dapat digunakan untuk menilai kualitas informasi antara lain adalah kelengkapan, keakuratan, ketepatan waktu, 4 ketersediaan, relevansi, konsistensi, dan data entry. Sedangkan kualitas layanan berfokus pada keseluruhan dukungan yang diterima oleh service provider sistem atau teknologi. Service quality dapat dinilai dengan kecepatan respon, jaminan, empati, dan tindak lanjut layanan.

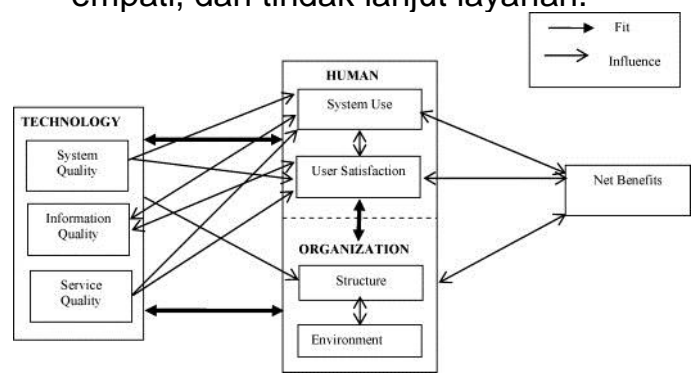

Gambar 3. Human Organization

Technology Fit (HOT Fit)

Sumber : (Yusof, 2006) $\begin{array}{ccc}\text { Model } & \text { evaluasi } & \text { terintegrasi } \\ \text { menggabungkan } & \text { variable } & \text { independen }\end{array}$ antara model penerimaan UTAUT, Model Kesuksesan SI Delone dan McLean, serta model kesesuaian Hot Fit (Mohamadali, 2010). Model UTAUT merupakan salah satu model terbaik dalam menjelaskan minat seseorang untuk menggunakan suatu sistem informasi teknologi dan perilaku pengguna berikutnya (Venkantesh et al., 2003). Sedangkan model Kesuksesan SI Delone dan McLean menjelaskan bahwa niat untuk menggunakan suatu sistem ditentukan oleh kualitas informasi, kualitas sistem, dan kualitas layanan serta telah menghubungkan penggunaan sistem dengan dampaknya (Mohamadali, 2010).

Model UTAUT dan model Kesuksesan masih memiliki kelemahan yakni kurangnya faktor kesesuaian antara manusiaorganisasi-teknologi. Menurut (Mohamadali, 2012) "Kesuksesan atau kegagalan sistem informasi sangat bergantung pada kesesuaian antara tiga tingkat yakni manusia-organisasi-teknologi".

Penggabungan faktor independen pada dua model serta penambahan model kesesuaian manusia-organisasi-teknologi menghasilkan model terintegrasi yang dapat memberikan representasi lebih baik atas faktor penentu niat pengguna. Model evaluasi terintegrasi ini dapat mengetahui dampak dari penggunaan sistem yang membagi faktor penentu menjadi tiga klasifikasi besar yakni manusia, organisasi, dan teknologi. Pengguna atau manusia perlu dievaluasi karena berhubungan langsung dengan sistem, organisasi perlu dievaluasi karena pengenalan teknologi informasi baru dapat mengubah layanan, operasi, dan struktur organisasi, dan teknologi perlu dievaluasi karena menjadi bagian dari sistem (Mohamadali, 2010).

\section{Model Evaluasi Terintegrasi}




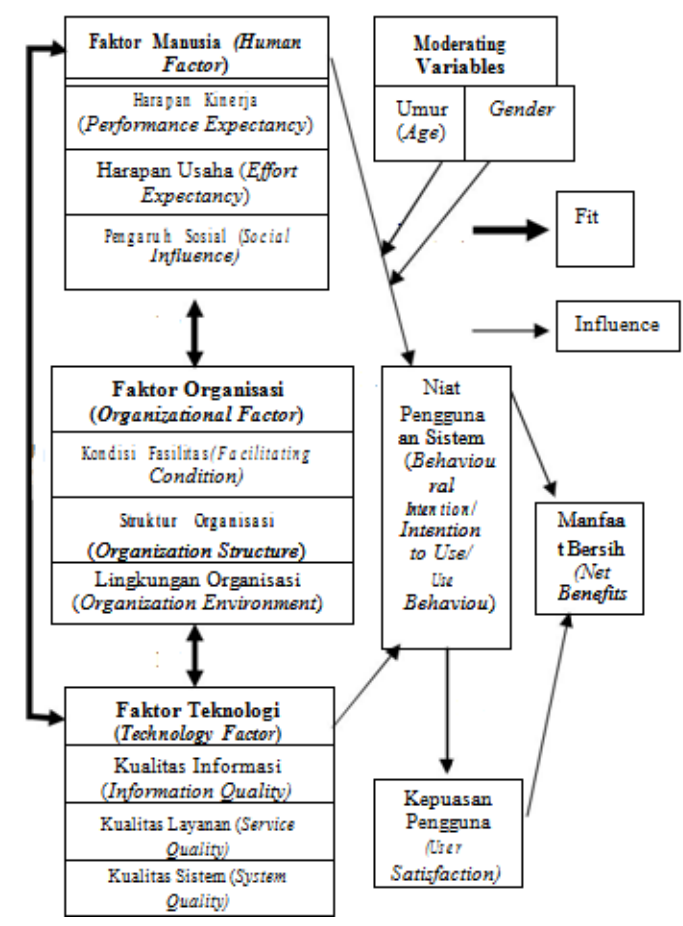

Gambar 4. Model Evaluasi Terintegrasi Sumber : (Mohamadali, 2010)

\section{E. Penelitian Terkait}

Penelitian yang dilakukan oleh Didit Mulyadi Mahyudin pada tahun 2015. Penelitian ini mengenai kepatuhan wajib pajak dengan diterapkannya program ESPT dalam melaporkan SPT masa PPN pada KPP Pratama Bitung. Hasil penelitian ini, menunjukan terdapat perbedaan atau hubungan yang signifikan antara kepatuhan wajib pajak sebelum dan sesudah penerapan e-SPT, yaitu pengguna e-SPT manual lebih dominan dibandingkan program e-SPT. Sehingga peneliti menyarankan Pimpinan Direktorat Jenderal Pajak beserta kantor wilayahnya sebaiknya dapat meningkatkan kinerja dengan memberikan penyuluhan mengenai pentingnya membayar pajak tepat waktu, serta memberikan layanan terbaiknya khusus bagi para wajib pajak.

Penelitian tentang pembayaran pajak secara online juga dilakukan oleh Finny Tania Rachdianti, Endang siti, dan Heru Susilo pada tahun 2016. Penelitian ini mengenai pengaruh penggunaan e-Tax terhadap kepatuhan wajib pajak. Hasil dari uji hipotesis menunjukan terdapat adanya pengaruh dari penggunaan e-Tax terhadap kepatuhan wajib pajak, namun pengaruh yang diberikan tidak signifikan.
Penelitian mengenai metode evaluasi terintegrasi juga pernah diteliti oleh Haris Pramugar, Wing Wahyu Winarno, dan Warsun Najib. Penelitian mengenai model evaluasi kesuksesan dan penerimaan sistem informasi e-Learning pada Lembaga Diklat Pemerintahan. Hasil penelitian ini menunjukan bahwa model evaluasi kesuksesan dan penerimaan SI e-learning pada lembaga diklat pemerintah dapat menggambarkan faktor-faktor yang mempengaruhi kesuksesan sistem informasi dan penerimaan pengguna terhadap sistem informasi serta dapat menggambarkan kesesuaian antara manusia, teknologi, dan organisasi.

\section{Hasil dan Pembahasan}

Hasil penelitian merupakan hasil dari perumusan masalah, perumusan hipotesis dan pengumpulan data berdasarkan hasil literatur, metode-metode dan analisis data yang dilakukan pada suatu objek penelitian.

\subsection{Profil Responden Penelitian}

Responden dalam penelitian ini adalah pegawai di lingkungan Dinas Pelayanan Pajak dan masyarakat Bandung yang telah menggunakan sistem informasi website sipp.disyanjak.bandung.go.id. Kuesioner yang disebar dalam penelitian ini sebanyak 200 link. Kuesioner yang mendapat tanggapan sebanyak 132 link dan yang tidak medapat tanggapan sebanyak 68 link. Dari 132 tanggapan yang kembali, terdapat 30 tanggapan yang diisi tidak lengkap. Namun berdasarkan teori Green, maka penulis akan mengolah sample sebanyak 100 link.

Tabel 1. Data sebaran kuesioner

\begin{tabular}{|l|l|c|}
\hline No. & \multicolumn{1}{|c|}{ Uraian } & Jumlah \\
\hline 1. & Kuesioner yang disebar & 200 \\
\hline 2. & $\begin{array}{l}\text { Kuesioner tidak diisi atau } \\
\text { tidak kembali }\end{array}$ & 68 \\
\hline 3. & $\begin{array}{l}\text { Kuesioner jawaban tidak } \\
\text { valid (tidak diisi lengkap) }\end{array}$ & 30 \\
\hline $\begin{array}{l}\text { Kuesioner jawaban valid } \\
\text { (diolah) }\end{array}$ & $\mathbf{1 0 0}$ \\
\hline
\end{tabular}

Sumber: Data Primer diolah, 2017

Dari 100 kuesioner yang diolah, dibuat klasifikasi responden berdasarkan jenis kelamin dan usia. Hasil pengumpulan data dapat dirinci pada tabel berikut ini : 
JURNAL SWABUMI, Vol. 7 No.1 Maret 2019, pp. 1 13

ISSN: 2355-990X

E-ISSN:2549-5178

8

Tabel 2. Data Responder Berdasar Jenis Kelamin

\begin{tabular}{|c|c|c|c|c|}
\hline No. & Klasifikasi & Pengukur & Jumlah & Presentase (\%) \\
\hline \multirow{2}{*}{1.} & \multirow{2}{*}{ Jenis Kelamin } & Laki-laki & 60 & $60 \%$ \\
\cline { 3 - 5 } & & Perempuan & 40 & $40 \%$ \\
\hline \multicolumn{2}{|c|}{ Total } & & \multicolumn{3}{|c|}{$100 / 100 \%$} \\
\hline \multirow{3}{*}{2.} & \multirow{3}{*}{ Usia } & $<29$ Tahun & 68 & $68 \%$ \\
\cline { 3 - 5 } & & $30-35$ Tahun & 20 & $19 \%$ \\
\cline { 3 - 5 } & & $36-40$ Tahun & 7 & $7 \%$ \\
\cline { 3 - 5 } & & $>40$ Tahun & 5 & $5 \%$ \\
\hline \multicolumn{3}{|c|}{ Total } & \multicolumn{3}{|c|}{$100 / 100 \%$} \\
\hline
\end{tabular}

Sumber: Data Primer diolah, 2017

Dapat diketahui bahwa dari 100 responden pengguna aplikasi website pajak online dalam penelitian ini di dominasi oleh responden laki-laki yaitu sebanyak 60 orang $(60 \%)$ dan responden berjenis kelamin perempuan sebanyak 40 orang $(40 \%)$. Berdasar klasifikasi responden dapat diketahui responden $<29$ tahun berjumlah 68 orang $(68 \%)$, responden $30-$ 35 tahun berjumlah 20 orang (19\%), responden $36-40$ tahun berjumlah 7 orang (7\%), dan responden $>40$ tahun berjumlah 5 orang $(5 \%)$. Berdasarkan data di atas dapat diketahui bahwa mayoritas responden yang menggunakan website sipp.disyanjak.bandung.go.id berusia di bawah 30 tahun sebanyak 68 responden (68\%).

\subsection{Analisis Deskriptif}

Deskriptif data yang disajikan dalam penelitian ini adalah gambaran secara umum mengenai perolehan dari hasil data penyebaran kuesioner kepada 100 responden. Data yang sifatnya kualitatif dianalisis dan dideskripsikan dalam bentuk ungkapan-ungkapan dan kalimat guna menggambarkan fenomena-fenomena yang muncul selama proses penelitian berlangsung.

\subsubsection{Tanggapan Responden Terhadap Kepuasan Satisfaction) \\ (User}

Tabel 3. Data Hasil skor kepuasan pengguna

\begin{tabular}{|c|c|c|c|}
\hline Variabel & Skor total variable & Variabel & Kategori \\
\hline $\mathrm{Y}_{2}$ & 1691 & Kepuasan Pengguna & Sangat Baik \\
\hline
\end{tabular}

Sumber: Data Primer diolah, 2017

Dapat diartikan, variabel kepuasan pengguna dikategorikan "Sangat Baik". Hal ini dapat disimpulkan bahwa responden puas menggunakan

sipp.disyanjak.bandung.go.id.

website

\subsection{Analisis Statistik}

\subsubsection{Uji Validitas dan Reliabilitas}

Uji validitas yang dilakukan dalam penelitian ini yaitu dengan menggunakan rumus korelasi bivariate pearson dengan alat bantu program SPSS versi 22. Item angket dalam uji validitas dikatakan valid jika harga $r$ hitung $>r$ tabel pada nilai signifikasi $5 \%$. Sebaliknya item dikatakan tidak valid jika harga $r$ hitung $<r$ tabel pada nilai signifikasi 5\%. Daftar $r$ tabel dapat dilihat di website www.spssindonesia.com.

Tabel 4. Data Hasil uji validitas kepuasan pengguna

\begin{tabular}{|c|c|c|c|}
\hline No Item & r hitung & r tabel 5\% (100) & Keterangan \\
\hline 1 & 0,852 & 0,195 & Valid \\
\hline 2 & 0,575 & 0,195 & Valid \\
\hline 3 & 0,564 & 0,195 & Valid \\
\hline 4 & 0,782 & 0,195 & Valid \\
\hline
\end{tabular}

Sumber: Data Primer diolah, 2017

Uji reliabilitas digunakan dengan menggunakan rumus alpha dan dapat dilihat dalam kolom tabel cronbach's Alpha. Uji signifikan dilakukan dengan taraf $\alpha=$ 0,005 . Instrumen dapat dikatakan reliabel jika nilai alpha lebih besar dari nilai rtabel $(0,195)$.

Tabel 5. Data Hasil uji reliabilitas instrumen pengguna

\begin{tabular}{|l|c|l|}
\hline \multicolumn{1}{|c|}{ Variabel } & Alpha & Keterangan \\
\hline Faktor Manusia (X1) & 0,788 & Reliabel \\
\hline Faktor Organisasi (X2) & 0,795 & Reliabel \\
\hline Faktor Teknologi (X3) & 0,849 & Reliabel \\
\hline Intention to use & 0,877 & Reliabel \\
\hline Kepuasan Penguna & 0,848 & Reliabel \\
\hline Net benefit & 0,748 & Reliabel \\
\hline
\end{tabular}

Sumber: Data Primer diolah, 2017

\subsubsection{Uji Normalitas}

Beberapa uji normalitas Menurut Priyanto (2012) uji normalitas bisa dilakukan dengan dua cara, yaitu dengan melihat penyebaran data pada sumber diagonal pada grafik normal P-P Plot of regresion standardized residual atau dengan uji One Sample Kolmogorov. 


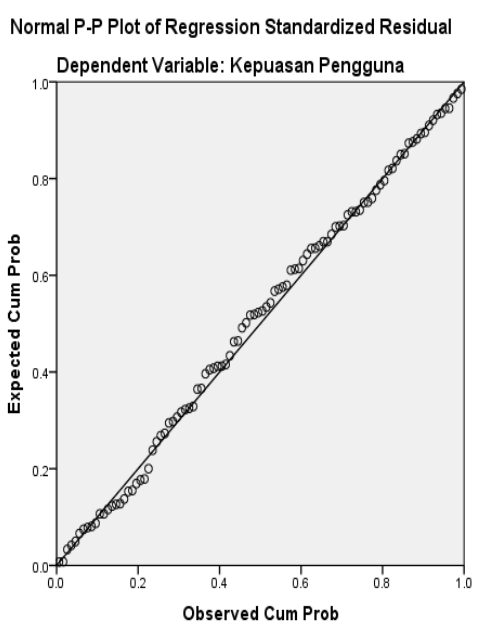

Gambar 5 . uji One Sample Kolmogorov Sumber : Data Primer Diolah, 2017

Dari grafik tersebut dapat diketahui bahwa titik-titik meyebar sekitar garis dan mengikuti garis diagonal maka nilai residual tersebut telah normal.

Tabel 6. Data Hasil uji normalitas kepuasan pengguna dengan One Sample Kolmogorov-Smimov Test

\begin{tabular}{|c|c|c|}
\hline & & $\begin{array}{c}\text { Unstandardzed } \\
\text { Resi/dual }\end{array}$ \\
\hline $\mathrm{N}$ & & 100 \\
\hline \multirow[t]{2}{*}{ Normal Parametersas } & Mean & .0000000 \\
\hline & Sta. Deviation & 1.70428690 \\
\hline \multirow[t]{3}{*}{ Most Extreme Differences } & Absolute & .043 \\
\hline & Positive & .045 \\
\hline & Negatve & -.043 \\
\hline Test Statstc & & .043 \\
\hline Asymp. Sig. (2-talled) & & 2005 \\
\hline
\end{tabular}

a. Test distioution is Norma.

b. Calculated from data

6. Uilietors Signitcance Correction

d. Tnis is a lower bound of the true signitcance

Sumber: Data Primer diolah, 2017

Dari hasil uji normalitas OneSample Kolmogorov-Smirnov Test di atas dapat diketahui bahwa nilai signifikasi (Asymp.Sig) sebesar 0,200. Karena signifikasi lebih dari $0,05 \quad(0,200>0,05)$, maka nilai residual tersebut telah normal.

\subsubsection{Uji Autokorelasi}

Tabel 7. Data Nilai statistik Durbin-Watson untuk uji Autokorelasi

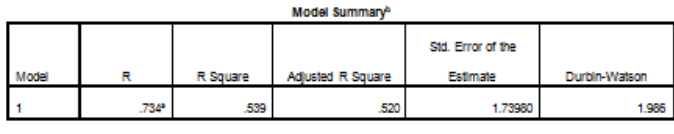

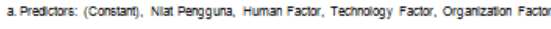

Dependent Variabe: Kepuasan Penguuna

Sumber: Data Primer diolah, 2017

Nilai statistik Durbin-Watson (D-W) $=1,986$, kemudian dilihat dari tabel Durbin Watson bahwa nilai dU adalah 1,780 dan nilai dL sebesar 1,571, maka kesimpulannya tidak terjadi autokorelasi, karena nilai Durbin-Watson 1,986 lebih besar dari batas atas (durbin Upper atau dU) yakni 1,780 dan kurang dari $(4-\mathrm{dU}) 4$ $-1,780=2,22$ sehingga dapat dinyatakan syarat regresi berganda telah terpenuhi. Disimpulkan bahwa tidak ada masalah autokorelasi pada model regresi. Maka, analisis pengguna berdistribusi normal.

\subsubsection{Uji Multikolinieritas}

Beberapa metode uji multikolineritas yaitu dengan melihat nilai Tolerance dan Inflation Factor (VIF) pada model regresi atau dengan membandingkan nilai koefisien determinasi individual $\left(r^{2}\right)$ dengan nilai determinasi secara serentak $\left(\mathrm{R}^{2}\right)$. Batas nilai VIF yaitu kurang dari 10 dan mempunyai angka tolerance lebih dari 0,1 .

Tabel 8. Data hasil pengujian Multikolinieritas Coefficients

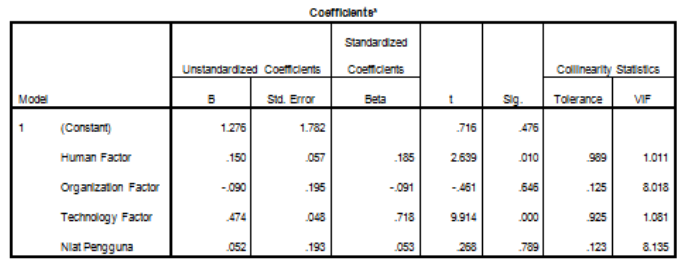

Sumber: Data Primer diolah, 2017

Dari tabel Coefficients diatas dapat diketahui bahwa nilai VIF dan nilai Tolerance yang diperoleh dari keempat variabel lebih dari 0,1 yaitu $(0,989>0,1)$, $(0,125>0,1),(0,925>0,1)$, dan $(0,123>$ $0,1)$ serta nilai VIF kurang dari 10. Maka dapat disimpulkan tidak terdapat multikolinieritas diantara keempat variabel bebas terhadap variable kepuasan pengguna.

\subsubsection{Uji Heteroskedastisitas}

Model regresi yang baik mensyaratkan tidak adanya masalah heteroskedastisitas. Untuk mengetahui ada 
tidaknya heteroskedastisitas dapat melihat scatterplot yaitu jika titik-titik menyebar dengan pola yang tidak jelas di atas dan di bawah angka nol pada sumbu $\mathrm{Y}$ maka dapat disimpulkan bahwa tidak terjadi masalah heteroskedastisitas pada model regresi.

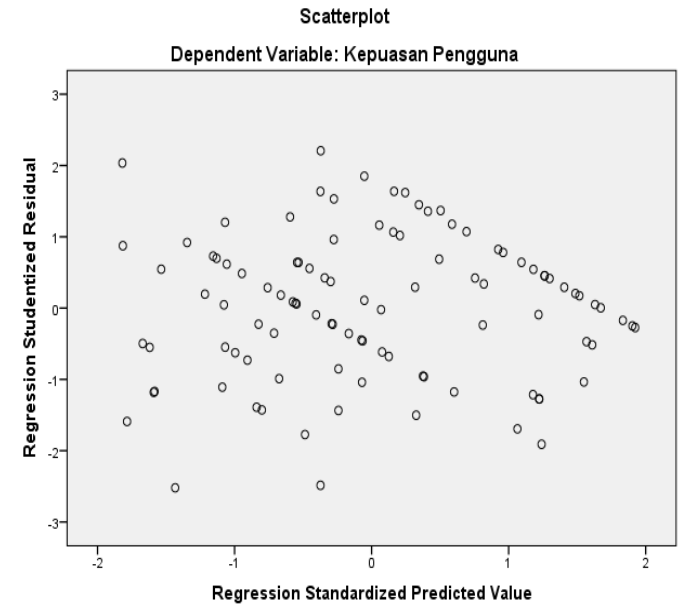

Gambar 6. Model Regresi

Sumber : Data Primer Diolah, 2017

\subsubsection{Uji Regresi Berganda}

Dalam regresi linier berganda terdapat asumsi klasik yang harus terpenuhi, yaitu residual terdistribusi normal, tidak adanya multikolineritas, tidak adanya heteroskedaktisitas, dan tidak adanya autokorelasi pada model regresi. Dan semua itu telah terpenuhi pada pembahasan sebelumnya.

Tabel 9. Data Koefisien determinasi kepuasan pengguna

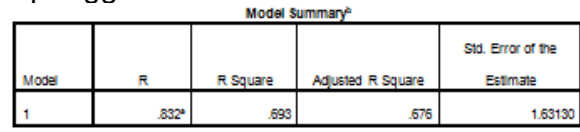

a. Presclors: (Constant), Kepuasan Pengguna, Organizaton Factor, Human Factor.

Technology Faclor, Niat Penggura

D. Dependent Varizole: Mantast Bers!

Sumber: Olah data penulis dengan SPSS versi 22

Output ini menjelaskan tentang ringkasan model, yang terdiri dari hasil nilai korelasi berganda $(R)$, koefisien determinasi $(R$ Square), koefisien determinasi yang disesuaikan (Adjusted $R$ Square), dan ukuran kesalahan prediksi (Std Error of the estimate).

$\mathbf{R}$ dalam regresi linier berganda dalam tabel diatas menunjukan nilai korelasi berganda, yaitu korelasi antara variabel Human factor $\left(\mathrm{X}_{1}\right)$, Organization factor $\left(\mathrm{X}_{2}\right)$, Technology factor $\left(\mathrm{X}_{3}\right)$, niat pengguna $\left(X_{4}\right)$, dan kepuasan pengguna $\left(X_{5}\right)$ secara simultan memengaruhi variabel manfaat bersih $(\mathrm{Y})$. Nilai $\mathrm{R}$ berkisar antara 0 sampai 1. Jika 1 mendekati 1 maka hubungan semakin kuat, tetapi jika mendekati 0 maka hubungan semakin lemah. Angka $\mathrm{R}$ dalam output diatas didapat 0,832 , artinya korelasi antara variabel variabel Human factor $\left(\mathrm{X}_{1}\right)$, Organization factor $\left(\mathrm{X}_{2}\right)$, Technology factor $\left(X_{3}\right)$, niat pengguna $\left(X_{4}\right)$, dan kepuasan pengguna $\left(X_{5}\right)$ secara simultan memengaruhi variabel manfaat bersih $(\mathrm{Y})$ sebesar 0,832. Hal ini berarti terjadi hubungan yang sangat erat, karena berdasarkan keeratan korelasi yang dikelompokan antara nilai 0,71 sampai 0,90 berarti korelasi memiliki keeratan sangat kuat. (Sujarweni,2015:127).

R Square (R2) atau kuadrat dari $\mathrm{R}$, yaitu menunjukan koefisien determinasi. Angka ini akan diubah ke bentuk persen, yang artinya persentase sumbangan pengaruh variabel independen terhadap variabel dependen. Nilai R2 sebesar 0,693 artinya persentase sumbangan pengaruh variabel Human factor $\left(\mathrm{X}_{1}\right)$, Organization factor $\left(X_{2}\right)$, Technology factor $\left(X_{3}\right)$, niat pengguna $\left(X_{4}\right)$, dan kepuasan pengguna $\left(X_{5}\right)$ secara simultan memengaruhi variabel manfaat bersih ( $\mathrm{Y}$ ) sebesar 59,3\%, sedangkan sisanya dipengaruhi oleh variabel lain yang tidak dimasukan dalam model ini.

Adjusted $\mathbf{R}$ Square, adalah $\mathrm{R}$ Square yang telah disesuaikan, nilai sebesar 0,676, ini juga menunjukan sumbangan pengaruh variabel independen terhadap variabel dependen.

Standard Error of the Estimate, adalah ukuran kesalahan prediksi, nilai sebesar 1,63130. Artinya kesalahan yang dapat terjadi dalam memprediksi kepuasan pengguna sebesar $1,631 \%$.

\subsubsection{Uji Hipotesis}

Uji t atau uji koefisien regresi secara parsial digunakan untuk mengetahui apakah secara parsial variabel independen berpengaruh secara signifikan atau tidak terhadap variabel dependen.

Tabel 10. Data pengujian T hitung kepuasan pengguna 


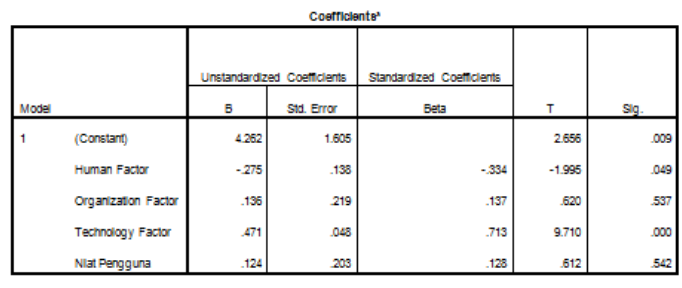

2.Dependent Varable: Kepuasan Penggur

$t_{\text {tabel }}=($ tinggkat kepercayaan dibagi $2 ;$ jumlah responden dikurangi jumlah variabel bebas dikurangi 1)

$\mathrm{t}_{\text {tabel }}=(\alpha / 2 ; \mathrm{n}-\mathrm{k}-1)$, tingkat kepercayaan yang digunakan adalah $95 \%$ jadi $\alpha$ $=0,05$

Sumber: Data Primer diolah, 2017

Dari output di dapat $\mathrm{t}$ hitung niat pengguna sebesar 0,612. Kemudian bandingkan dengan t tabel. $\mathrm{T}$ tabel dicari pada signifikasi $0,05 / 2=0,025$ (uji 2 sisi) dengan derajat kebebasan $\mathrm{df}=\mathrm{n}-\mathrm{k}-1$ atau $100-5-1=94$. Hasil diperoleh untuk t tabel dalam distribusi nilai ttbael sebesar 1,988 / 1,988. Untuk kriteria pengujian sebagai berikut;

- Jika H0 diterima dan H1 ditolak maka

thitung $<t_{\text {tabel }}$ atau jika nilai Sig. $>0,05$

- Jika H0 ditolak dan H1 diterima maka

thitung $>$ tabel atau jika nilai Sig. $<0,05$

Karena nilai $\mathrm{t}$ hitung $<\mathrm{t}$ tabel $(0,612<$ 1,985) maka Ho diterima. Jadi dapat disimpulkan bahwa niat pengguna (Intention to use / Use Behavioral) tidak berpengaruh signifikan terhadap kepuasan pengguna.

Pengambilan keputusan berdasar signifikasi

Berdasar signifikasi, jika signifikasi < 0,05 maka Ho ditolak, dan jika signifikasi > 0,05 maka Ho diterima. Karena signifikasi pada uji t lebih dari 0,05 (0,54 > 0,05) maka Ho diterima. Artinya niat pengguna (Intention to use / Use Behavioral) tidak berpengaruh signifikan terhadap kepuasan pengguna.

\section{Kesimpulan}

Berdasarkan penelitian yang telah dilakukan kepada pengguna website sipp.disyanjak.bandung.go.id di Kota Bandung, mengenai kepuasan pengguna website sipp.disyanjak.bandung.go.id sebagai sarana informasi tentang pajak dengan menggunakan model evaluasi terintegrasi dari model Unified Theory of Acceptance and use of Technology (UTAUT), model kesuksesan SI DeLone dan McLean, dan model kesesuaian manusia-organisasi-teknologi HOT Fit, maka dapat ditarik kesimpulan sebagai berikut:

1. Pengujian yang dilakukan menghasilkan nilai koefisien pengaruh faktor manusia (Human Factor) terhadap niat penggunaan (Behavioral Intention / Intention to Use) website sipp.disyanjak.bandung.go.id sebesar 2,837. Dari hasil penelitian ini dapat diketahui bahwa faktor manusia (Human factor), berpengaruh signifikan terhadap niat pengguna (Behavioral to Use / Intention to Use). Dan setelah pengujian hipotesis, dengan melakukan uji t (uji koefisien regresi secara parsial) dengan mendapat hasil bahwa $t$ hitung sebesar 2,837 dan $t$ tabel 1,988. Karena t hitung $>t$ tabel $(2,837>1,985)$ maka pengujian hipotesis dinyatakan signifikan sehingga dapat disimpulkan bahwa terdapat korelasi yang positif antara faktor manusia (Human Factor) dan niat penggunaan (Behavioral to Use / Intention to Use). Hal ini menunjukan bahwa faktor manusia (Human Factor) menjadi variabel penting yang di pertimbangkan dalam niat penggunaan. (Behavioral to Use / Intention to Use).

Pengujian yang dilakukan menghasilkan nilai koefisien pengaruh faktor organisasi (Organization Factor) terhadap niat penggunaan (Behavioral to Use / Intention to Use) website sipp.disyanjak.bandung.go.id sebesar 9,311. Dari hasil penelitian ini dapat diketahui bahwa faktor organisasi (Organization factor), berpengaruh signifikan terhadap niat pengguna (Behavioral to Use / Intention to Use). Dan setelah pengujian hipotesis, dengan melakukan uji t (uji koefisien regresi secara parsial) dengan mendapat hasil bahwa $t$ hitung sebesar 9,311 dan t tabel 1,988. Karena $\mathrm{t}$ hitung $>\mathrm{t}$ tabel $(9,311>1,985)$ maka pengujian hipotesis dinyatakan signifikan sehingga dapat disimpulkan bahwa terdapat korelasi yang positif antara faktor organisasi (Organization Factor) dan niat penggunaan (Behavioral to Use / Intention to Use). Hal ini menunjukan bahwa secara organisasi Dinas Pelayanan Pajak telah mendukung implementasi website sipp.disyanjak.bandung.go.id dengan menyediakan fasilitas berupa sarana dan prasarana serta fitur website yang lengkap.

Pengujian yang dilakukan menghasilkan nilai koefisien pengaruh 
faktor teknologi terhadap niat penggunaan website sipp.disyanjak.bandung.go.id sebesar 2,548. Dari hasil penelitian ini dapat diketahui bahwa faktor teknxologi (Technology factor), berpengaruh signifikan terhadap niat pengguna (Behavioral to Use / Intention to Use). Dan setelah pengujian hipotesis, dengan melakukan uji t (uji koefisien regresi secara parsial) dengan mendapat hasil bahwa $t$ hitung sebesar 2,548 dan $t$ tabel 1,988. Karena t hitung $>t$ tabel $(2,548>1,985)$ maka pengujian hipotesis dinyatakan signifikan sehingga dapat disimpulkan bahwa terdapat korelasi yang positif antara faktor teknologi (Technology Factor) dan niat penggunaan (Behavioral to Use / Intention to Use). Hal ini menunjukan bahwa faktor teknologi (Technology Factor) merupakan variabel yang penting untuk dipertimbangkan dalam niat penggunaan.

2. Pengujian yang dilakukan menghasilkan nilai koefisien pengaruh niat pengguna (Behavioral to Use / Intention to Use) terhadap kepuasan pengguna (User Satisfaction) website sipp.disyanjak.bandung.go.id sebesar 0,612 . Dari hasil penelitian ini dapat diketahui bahwa niat pengguna (Behavioral to Use / Intention to Use), tidak berpengaruh signifikan terhadap kepuasan pengguna (User Satisfaction). Dan setelah pengujian hipotesis, dengan melakukan uji t (uji koefisien regresi secara parsial) dengan mendapat hasil bahwa $t$ hitung sebesar 0,612 dan $t$ tabel 1,988. Karena thitung $<\mathrm{t}$ tabel $(0,612<1,985)$ dan pada tingkat signifikansi lebih besar dari 0,05 yaitu 0,54, sehingga niat pengguna (Behavioral to Use / Intention to Use) dinyatakan tidak signifikan terhadap kepuasan pengguna (User Satisfaction). Sementara koefisien jalur bernilai 0,612 yang membuktikan bahwa terdapat korelasi yang positif antara niat penggunaan (Behavioral to Use / Intention to Use) dengan kepuasan pengguna (User Satisfaction). Hasil pengujian diperoleh bahwa niat penggunaan (Behavioral to Use / Intention to Use) memiliki korelasi positif namun tidak berpengaruh terhadap kepuasan pengguna (User Satisfaction) website sipp.disyanjak.bandung.go.id. Hal ini menunjukkan bahwa niat penggunaan (Behavioral to Use / Intention to Use) bukan variabel penting yang dipertimbangkan dalam kepuasan pengguna (User Satisfaction).

3. Pengujian yang dilakukan menghasilkan nilai koefisien pengaruh kepuasan pengguna (User Satisfaction) terhadap manfaat bersih ( $\mathrm{Net}$ benefit) website sipp.disyanjak.bandung.go.id sebesar -1,254. Dari hasil penelitian ini dapat diketahui bahwa kepuasan pengguna (User Satisfaction) tidak berpengaruh signifikan terhadap manfaat bersih ( Net Benefit). Dan setelah pengujian hipotesis, dengan melakukan uji $t$ (uji koefisien regresi secara parsial) dengan mendapat hasil bahwa t hitung sebesar $-1,254$ dan $\mathrm{t}$ tabel $-1,988$. Karena $t$ hitung $<\mathrm{t}$ tabel $(-$ $1,254<-1,985)$ dan pada tingkat signifikansi lebih besar dari 0,05 yaitu 0,21, sehingga kepuasan pengguna (User Satisfaction) dinyatakan tidak signifikan terhadap manfaat bersih (Net Benefit). Hal ini membuktikan bahwa terdapat korelasi yang positif antara kepuasan penggunaan (User Satisfaction) dengan manfaat bersih (Net Benefit). Hasil pengujian diperoleh bahwa kepuasan penggunaan (User Satisfaction) memiliki korelasi positif tetapi tidak berpengaruh terhadap manfaat bersih (Net Benefit) website sipp.disyanjak.bandung.go.id.

4. Pengujian yang dilakukan menghasilkan nilai koefisien kesesuaian antara faktor manusia (Human Factor) dengan faktor teknologi (Technology Factor) yaitu sebesar 0,62. Hasil ini menunjukkan bahwa korelasi manusia dan teknologi kuat. Hal ini dikarenakan faktor manusia (Human Factor) mempunyai hubungan erat dengan faktor teknologi (Technology Factor) dimana manusia sebagai pengguna bersentuhan langsung dengan sistem.

Pengujian yang dilakukan menghasilkan nilai koefisien kesesuaian antara faktor organisasi (Organization Factor) dengan faktor teknologi (Technology Factor) yaitu sebesar 0,19. Hasil ini menunjukkan bahwa korelasi antara faktor organisasi (Organization Factor) dengan faktor teknologi (Technology Factor) sangat lemah.

Pengujian yang dilakukan menghasilkan nilai koefisien kesesuaian antara faktor manusia (Human Factor) dengan faktor organisasi (Organization Factor) yaitu sebesar 0,84. Hasil ini menunjukkan bahwa korelasi antara faktor 
JURNAL SWABUMI, Vol. 7 No.1 Maret 2019, pp. 1 13

ISSN: 2355-990X

E-ISSN:2549-5178

13

manusia (Human Factor) dengan faktor organisasi (Organization Factor) sangat kuat. Hal ini dikarenakan organisasi adalah sekumpulan manusia secara formal beserta sumber-sumber pendukung yang tidak dapat dipisahkan untuk mencapai tujuan manajemen, visi dan misi organisasi yang telah ditetapkan.

\section{Referensi}

Brown, S. A. (2005). Model of Adoption of Technology in the Household A Baseline Model Test and Extension Incorporating Household Life Cycle. MIS Quarterly (29:4), pp , 399-426.

Elvandari, D. S. (2011). Adaptasi Model Delone Dan Mclean Yang Dimodifikasi Guna Menguji Keberhasilan Implementasi Aplikasi Operasional Bank Bagi Individu Pengguna: Studi Empiris Pada Bank Umum Di Kota Semarang.

F.Kursehi, \&. S. (2013). Evaluasi Kesuksesan Sistem Informasi ERP pada Usaha Kecil Menengah Studi Kasus: Implementasi SAP BI.

Jogiyanto. (2007). Model Kesuksesan Sistem Teknologi Informasi. Yogyakarta: Andi.

McLean, W. H. (1992). Information Systems Success: The Quest for the Dependent Variable. Information Systems Research, pp. , 60-95.

McLean., W. H. (2003). The DeLone and McLean Model of Information Systems Success: A Ten-Year Update. Journal of Management Information Systems .

Mohamadali, N. A. (2010). A Novel Evaluation Model of User Acceptance of Software Technology In Healthcare Sector. International Conference on Health Informatics .

Mohamadali, N. A. (2012). Understanding and Addressing The 'Fit' Between User, Technology, and Organization in Evaluating User Acceptance of Healthcare Technology. International Conference on Health Informatics

Neolaka, A. (2014). Metode Penelitian dan Statistik. Bandung: Remaja Rosdakarya.

Resmi, S. (2015). Perpajakan. Jakarta: Salemba Empat.

Soemitro, S. (2014). Analisis Ekonomi Jawa Barat. Bandung: Unpad Press.
Venkatesh, V. (2003). User Acceptance of Information Technology: Toward a Unified view. MIS Quarterly (27:3),pp. , 425-278.

Yuliasari, E. (2014). Analisis Faktor Determinan Penggunaan Sistem Aplikasi. 84.

Yusof, M. M. (2006). Towards a Framework for Health Information Systems Evaluation. Proceedings of the 39th Hawaii International Conference on System Sciences

Yustisia, T. V. (2015). Undang-undang Nomor 23 Tahun 2014 Tentang Pemerintahan Daerah dan Perubahannya. Jakarta: PT Visimedia Pustaka. 